
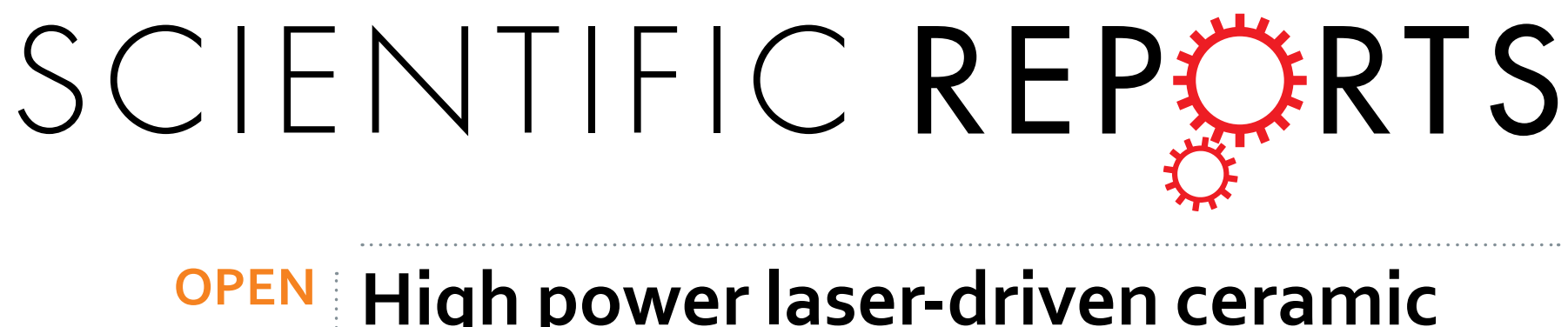

\title{
High power laser-driven ceramic phosphor plate for outstanding efficient white light conversion in \\ application of automotive lighting
}

Received: 16 February 2016

Accepted: 14 July 2016

Published: 09 August 2016
Young Hyun Song ${ }^{1, *}$, Eun Kyung $\mathrm{Ji}^{2}{ }^{2,}$, Byung Woo Jeong ${ }^{3,}{ }^{,}$, Mong Kwon Jung ${ }^{4,}{ }^{,}$, Eun Young Kim ${ }^{3}$ \& Dae HoYoon ${ }^{1,2}$

We report on $\mathrm{Y}_{3} \mathrm{Al}_{5} \mathrm{O}_{12}: \mathrm{Ce}^{3+}$ ceramic phosphor plate (CPP) using nano phosphor for high power laser diode (LD) application for white light in automotive lighting. The prepared CPP shows improved luminous properties as a function of $\mathrm{Ce}^{3+}$ concentration. The luminous properties of the $\mathrm{Y}_{3} \mathrm{Al}_{5} \mathrm{O}_{12}: \mathrm{Ce}^{3+}$ CPP nano phosphor are improved when compared to the $\mathrm{Y}_{3} \mathrm{Al}_{5} \mathrm{O}_{12}: \mathrm{Ce}^{3+} \mathrm{CPP}$ with bulk phosphor, and hence, the luminous emittance, luminous flux, and conversion efficiency are improved. $\mathrm{The}_{3} \mathrm{Al}_{5} \mathrm{O}_{12}$ : $\mathrm{Ce}^{3+} \mathrm{CPP}$ with an optimal $\mathrm{Ce}^{3+}$ content of $0.5 \mathrm{~mol} \%$ shows $2733 \mathrm{Im} / \mathrm{mm}^{2}$ value under high power blue radiant flux density of $19.1 \mathrm{~W} / \mathrm{mm}^{2}$. The results indicate that $\mathrm{Y}_{3} \mathrm{Al}_{5} \mathrm{O}_{12}: \mathrm{Ce}^{3+} \mathrm{CPP}$ using nano phosphor can serve as a potential material for solid-state laser lighting in automotive applications.

Solid state lighting (SSL) has attracted much interest since the first development of light emitting diodes (LED) using blue-emitting InGaN by S. Nakamura in $1995^{1}$. White LEDs are good candidates as lighting devices capable of replacing incandescent and fluorescent lamps due to their outstanding properties, such as long lifetimes, high luminance and compactness ${ }^{2-6}$. Generally, white light can be generated with blue-emitting devices and yellow emitting phosphor $\left(\mathrm{Y}_{3} \mathrm{Al}_{5} \mathrm{O}_{12}: \mathrm{Ce}^{3+}\right)^{7}$. The high efficiency of $\mathrm{Y}_{3} \mathrm{Al}_{5} \mathrm{O}_{12}: \mathrm{Ce}^{3+}$ phosphor facilitates the better luminescence performance in white LEDs. However, $\mathrm{Y}_{3} \mathrm{Al}_{5} \mathrm{O}_{12}: \mathrm{Ce}^{3+}$ phosphor in white LEDs exhibits problems associated with thermal quenching due to the higher operating current of LEDs ${ }^{8}$. With the decrease of LED efficiency as a function of higher operating current, the temperature of the LEDs increases and this efficiency is lost as heat. The increase of temperature in LEDs has significant effects on the $\mathrm{Y}_{3} \mathrm{Al}_{5} \mathrm{O}_{12}: \mathrm{Ce}^{3+}$ phosphor such as a decrease in efficiency and a possible shift of emission wavelength. Overall, the system efficiency of LEDs decreases and it is difficult to apply $\mathrm{Y}_{3} \mathrm{Al}_{5} \mathrm{O}_{12}$ : $\mathrm{Ce}^{3+}$ phosphor in high power LEDs. In contrast with LEDs, laser diodes (LD) can easily resolve the issues of LEDs. The output power and external quantum efficiency (EQE) of laser diodes increase linearly as a function of operating current, and the colour stability of the laser emission peak is maintained ${ }^{9,10}$. These characteristics make $\mathrm{Y}_{3} \mathrm{Al}_{5} \mathrm{O}_{12}: \mathrm{Ce}^{3+}$ phosphor an attractive excitation source for new high-power $\mathrm{LD}$ in white light applications. For the generation of white light, the thermal stability of $\mathrm{Y}_{3} \mathrm{Al}_{5} \mathrm{O}_{12}$ : $\mathrm{Ce}^{3+}$ phosphor is required in addition to blue LDs. In other words, it is necessary to avoid the use of organic resin with phosphor powders such as epoxy and silicone. An alternative to high power LDs in white light applications is to use the phosphor in glass and ceramic phosphor plates, similar to remote phosphor ${ }^{11}$. Phosphor in glass is not suitable for application to high power LDs because the luminous flux of the phosphor in glass gradually decreases at $>1.0 \mathrm{~W} /$ $\mathrm{mm}^{2}$ due to thermal quenching ${ }^{12}$. Ceramic phosphor plate (CPP) is combined with a laser diode because it is very different from high power blue laser diodes, which provide both optical and thermal stability compared with the mixture of organic resin with phosphor. To fabricate the CPP using bulk-type phosphor, solid state reaction method is required at high temperature ${ }^{13}$. This is a relatively simple method to fabricate the CPP but it is not easy to control the small grain size $(<1 \mu \mathrm{m})$ due to the initial size of phosphor. To lower the sintering temperature, it is imperative to use the nano-structured $\mathrm{Y}_{3} \mathrm{Al}_{5} \mathrm{O}_{12}: \mathrm{Ce}^{3+}$ phosphor. Previous works have demonstrated synthetic

${ }^{1}$ School of Advanced Materials Science \& Engineering, Sungkyunkwan University, Suwon 440-746, Republic of Korea. ${ }^{2}$ SKKU Advanced Institute of Nanotechnology (SAINT), Sungkyunkwan University, Suwon 440-746, Korea. ${ }^{3}$ LG Electronics, Material \& Device Advanced Research Institute Advanced Optics Team, Seoul 137-724, Korea. ${ }^{4}$ Hyosung Corporation, R \& D Business Labs, Anyang 431-080, Republic of Korea. *These authors contributed equally to the work. Correspondence and requests for materials should be addressed to D.-H.Y. (email: dhyoon@skku.edu) 


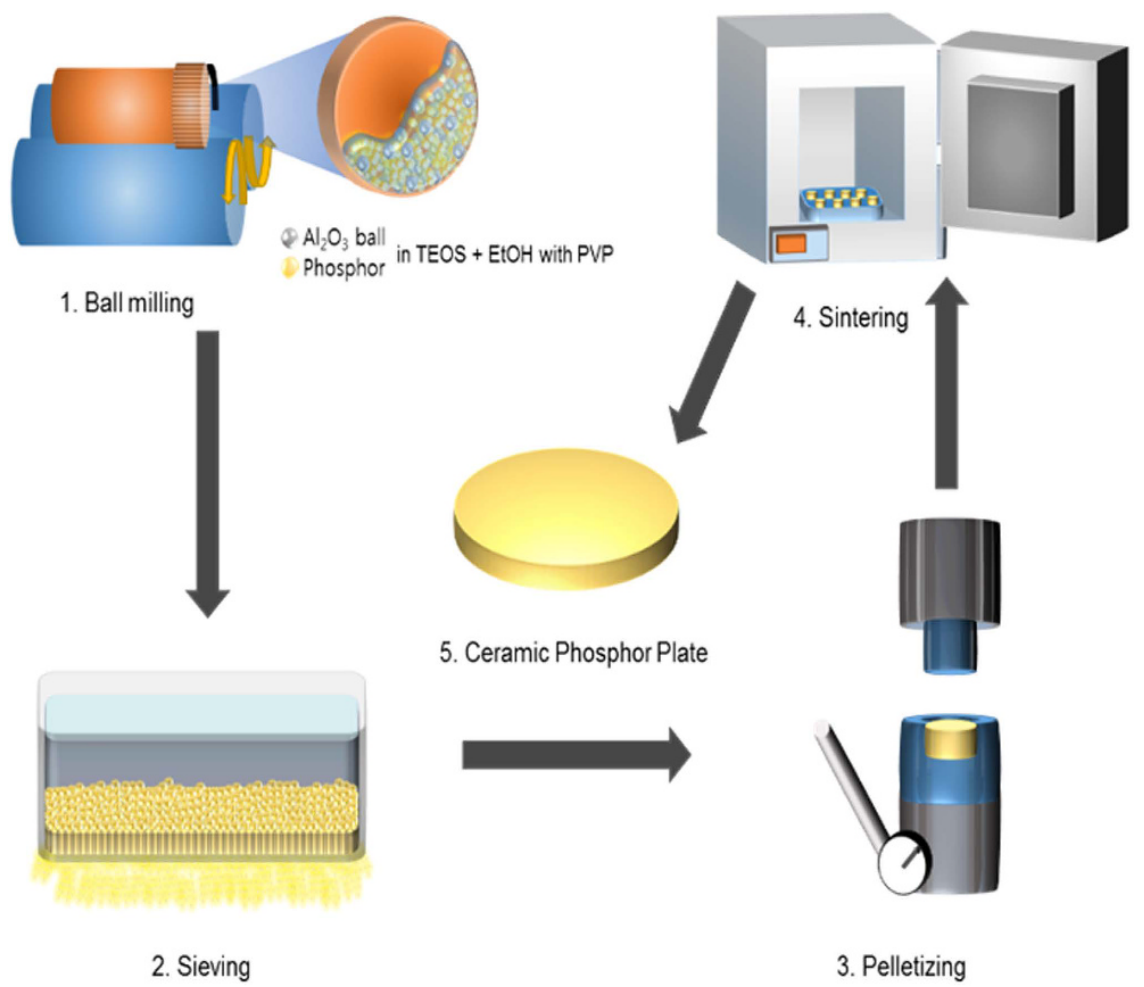

Figure 1. The schematic diagram of process for fabrication of nano-structure based $\mathrm{Y}_{3} \mathrm{Al}_{5} \mathrm{O}_{12}: \mathrm{Ce}^{3+}$ ceramic phosphor plate.

techniques such as co-precipitation, sol-gel, and combustion and spray pyrolysis methods ${ }^{14-17}$. These have been proposed as lower temperature synthesis methods for achieving the nano-structured single phase. Many scientists reported the luminous efficacy of $\mathrm{Y}_{3} \mathrm{Al}_{5} \mathrm{O}_{12}: \mathrm{Ce}^{3+} \mathrm{CPP}$ in LED applications when using bulk $\mathrm{Y}_{3} \mathrm{Al}_{5} \mathrm{O}_{12}: \mathrm{Ce}^{3+18-20}$. However, the $\mathrm{Y}_{3} \mathrm{Al}_{5} \mathrm{O}_{12}: \mathrm{Ce}^{3+} \mathrm{CPP}$ for white light generation in blue LD applications such as display, lamp, light fidelity, and automotive lighting sections have yet to be investigated in detail ${ }^{21,22}$. In this paper, we report our advanced research on $\mathrm{Y}_{3} \mathrm{Al}_{5} \mathrm{O}_{12}: \mathrm{Ce}^{3+} \mathrm{CPP}$ using nano-structured $\mathrm{Y}_{3} \mathrm{Al}_{5} \mathrm{O}_{12}: \mathrm{Ce}^{3+}$ precursor directly combined with blue LDs for white light generation. We substitute the mixture of organic resin with phosphor powder to $\mathrm{Y}_{3} \mathrm{Al}_{5} \mathrm{O}_{12}: \mathrm{Ce}^{3+} \mathrm{CPP}$. We also optimize the optical properties of $\mathrm{Y}_{3} \mathrm{Al}_{5} \mathrm{O}_{12}: \mathrm{Ce}^{3+} \mathrm{CPP}$.

\section{Experimental}

Preparation of the Nano-structured $\mathrm{Y}_{3} \mathrm{Al}_{5} \mathrm{O}_{12}: \mathrm{Ce}^{3+}$ phosphors. Nano-structured $\mathrm{Y}_{3} \mathrm{Al}_{5} \mathrm{O}_{12}: \mathrm{Ce}^{3+}$ phosphors were synthesized using the forced hydrolysis method. First, aluminum nitrate nonahydrate (SigmaAldrich, $\geq 98 \%$ pure), aluminum sulfate octadecahydrate (Sigma-Aldrich, $\geq 98 \%$ pure) and urea (Sigma-Aldrich, 99.5\%) were used to obtain the nano-structured $\mathrm{Al}(\mathrm{OH})_{3}$ particles. These materials were dissolved in deionized water and aged at $98^{\circ} \mathrm{C}$ for $4 \mathrm{~h}$. The precipitate was then separated through centrifugation and washed several times with both deionized water and ethanol. Next, yttrium nitrate (Sigma-Aldrich, 99.8\%), cerium nitrate (Sigma-Aldrich, 99\%), and urea (Sigma-Aldrich, 99.5\%) were used to dissolve the above materials in deionized water. The synthesized $\mathrm{Al}(\mathrm{OH})_{3}$ particles were homogeneously dispersed in the mixed solution, which was vigorously stirred at $98^{\circ} \mathrm{C}$ for $3 \mathrm{~h}$. The precipitate was isolated via centrifugation, washed with both deionized water and ethanol, and then dried using a lyophilizer. The resulting powder was annealed at $1200^{\circ} \mathrm{C}$ for $4 \mathrm{~h}$ under a reducing nitrogen atmosphere containing $5 \% \mathrm{H}_{2}$ gas. To compare the luminous properties, we synthesized bulk type $\mathrm{Y}_{3} \mathrm{Al}_{5} \mathrm{O}_{12}: \mathrm{Ce}^{3+}$ phosphor via solid state reaction method at at $1450{ }^{\circ} \mathrm{C}$ for $12 \mathrm{~h}$ under same condition.

Fabrication of the $\mathrm{Y}_{3} \mathrm{Al}_{5} \mathrm{O}_{12}: \mathrm{Ce}^{3+} \mathrm{CPP}$. The procedure for fabricating the $\mathrm{Y}_{3} \mathrm{Al}_{5} \mathrm{O}_{12}: \mathrm{Ce}^{3+} \mathrm{CPP}$ is shown in Fig. 1. The fabrication of $\mathrm{Y}_{3} \mathrm{Al}_{5} \mathrm{O}_{12}: \mathrm{Ce}^{3+} \mathrm{CPP}$ was carried out by ball milling nano-structured $\mathrm{Y}_{3} \mathrm{Al}_{5} \mathrm{O}_{12}$ : $\mathrm{Ce}^{3+}$ phosphor and $\mathrm{SiO}_{2}$ as a sintering aid. During this process, ethanol was used as a solvent at a weight ratio of powder:ethanol (1:5). All materials were mixed and milled with a ball milling machine using $\mathrm{ZrO}_{2}$ balls with a diameter of $5 \mathrm{~mm}$ for $24 \mathrm{~h}$. These mixtures were dried at $90^{\circ} \mathrm{C}$ for $12 \mathrm{~h}$ and compressed into a pellet using uniaxially pressed under $20 \mathrm{MPa}$ with a diameter of $10 \mathrm{~mm}$ and a thickness of $5 \mathrm{~mm}$. The pellets were fired at $1000^{\circ} \mathrm{C}$ for $6 \mathrm{~h}$ under air atmosphere to remove organic materials and then cold isostatically pressed under $300 \mathrm{MPa}$ for $30 \mathrm{~min}$. The green bodies were sintered with a graphite-heated vacuum furnace $\left(10^{-3} \mathrm{~Pa}\right)$ at $1600^{\circ} \mathrm{C}$ for $12 \mathrm{~h}$. The $\mathrm{Y}_{3} \mathrm{Al}_{5} \mathrm{O}_{12}$ : $\mathrm{Ce}^{3+} \mathrm{CPP}$ sintered to remove oxygen vacancies was annealed at $1450^{\circ} \mathrm{C}$ for $24 \mathrm{~h}$ under air atmosphere. Finally, all samples were mirror-polished on both surfaces.

Measurements and Characterization. The crystalline phase of the nano-structured $\mathrm{Y}_{3} \mathrm{Al}_{5} \mathrm{O}_{12}$ : $\mathrm{Ce}^{3+}$ phosphor was identified using powder X-ray diffraction (XRD, D-MAX 2500, Rigaku) with the CuK $\alpha$ target 

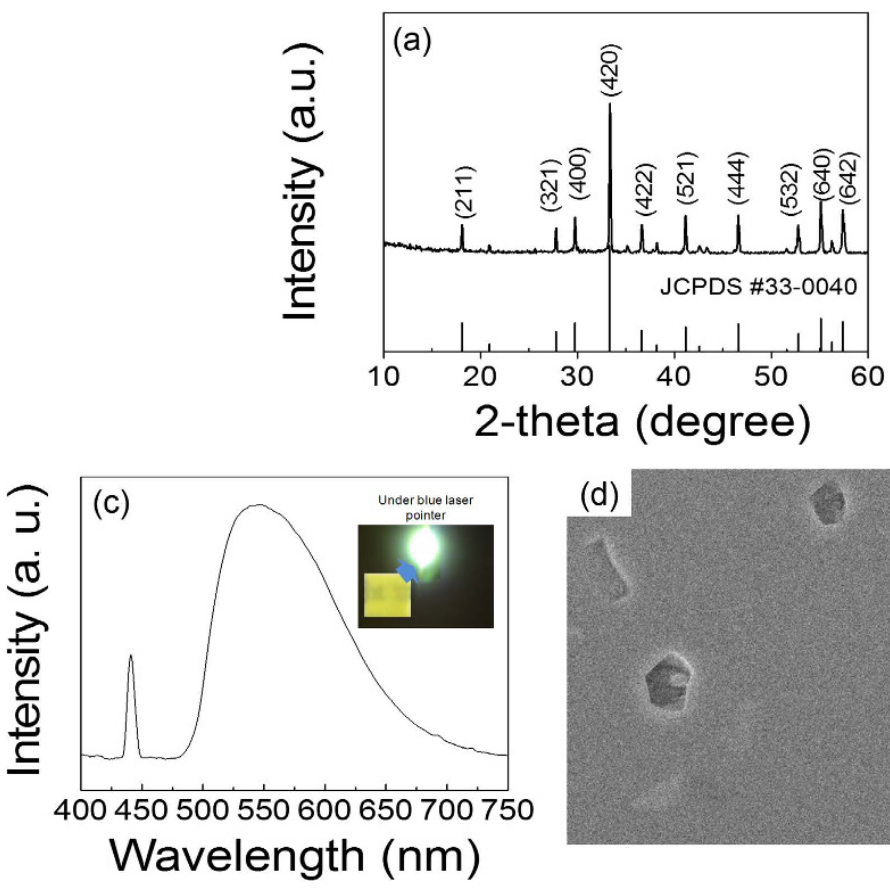

(d)

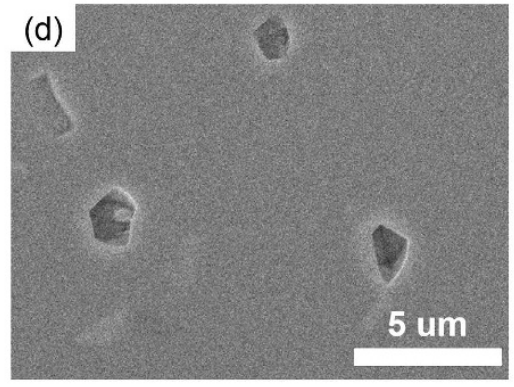

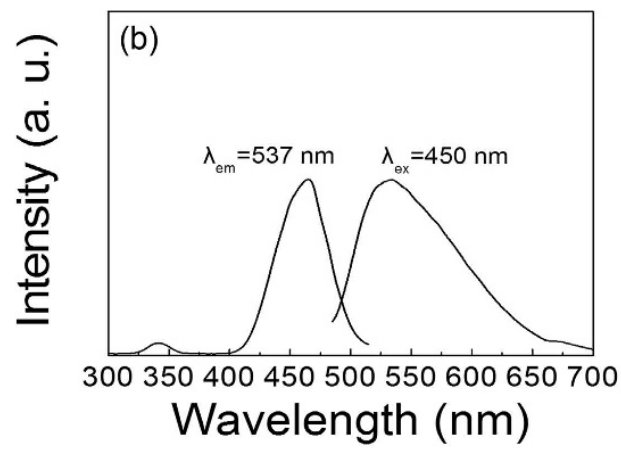

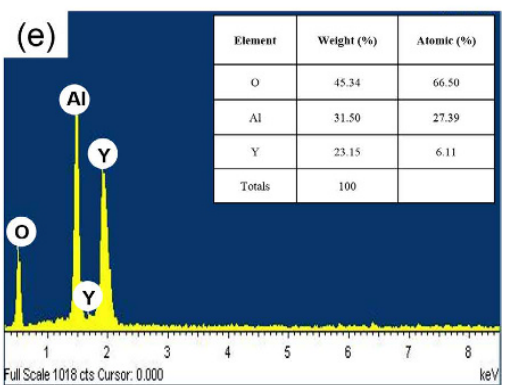

Figure 2. Structure, luminescence, and morphology of fabricated nano-structure based $\mathrm{Y}_{3} \mathrm{Al}_{5} \mathrm{O}_{12}: \mathrm{Ce}^{3+}$ ceramic phosphor plate. (a) XRD patterns (b) PL excitation and emission spectra (c) Electroluminescence spectra (d) SEM image (e) EDX analysis.

aligned to $10^{\circ} \leq 2 \theta \leq 80^{\circ}$. The excitation and emission spectra of the nano-structured $\mathrm{Y}_{3} \mathrm{Al}_{5} \mathrm{O}_{12}: \mathrm{Ce}^{3+}$ phosphor were analyzed by room-temperature photoluminescence spectrometry (PL, PSI Co., Ltd/Korea), using a $500 \mathrm{~W}$ xenon discharge lamp as an excitation source. The surface morphology and the compositions of the $\mathrm{Y}_{3} \mathrm{Al}_{5} \mathrm{O}_{12}$ : $\mathrm{Ce}^{3+} \mathrm{CPP}$ was observed by field-emission scanning electron microscopy (FE-SEM, JSM-7600F, JEOL, Japan). The luminous emittance, luminous flux and conversion efficiency of $\mathrm{Y}_{3} \mathrm{Al}_{5} \mathrm{O}_{12}: \mathrm{Ce}^{3+} \mathrm{CPP}$ was measured with double integrating spheres (PSI Co., Ltd/Korea) under blue laser excitation (3.5 W LD x 8, $445 \mathrm{~nm}$ blue LD) using handmade equipment from LG electronics.

\section{Results and Discussion}

The crystal structure of $\mathrm{Y}_{3} \mathrm{Al}_{5} \mathrm{O}_{12}: \mathrm{Ce}^{3+} \mathrm{CPP}$ was initially analyzed using the powder XRD with a CuK $\alpha$ radiation of $\lambda=1.5406 \AA$ at $10^{\circ} \leq 2 \theta \leq 80^{\circ}$ as shown in Fig. 2a. The XRD patterns of the obtained sample at $2 \theta=18.1^{\circ}, 27.6^{\circ}, 29.7^{\circ}, 33.3^{\circ}, 36.4^{\circ}, 41.0^{\circ}, 46.6^{\circ}, 55.1^{\circ}$ and $57.4^{\circ}$ were completely indexed pure $\mathrm{Y}_{3} \mathrm{Al}_{5} \mathrm{O}_{12}$ phase (JCPDS No. 33-0040) without any peaks assigned to the $\mathrm{CeO}_{2}, \mathrm{Y}_{2} \mathrm{O}_{3}, \mathrm{Al}_{2} \mathrm{O}_{3}, \mathrm{YAlO}_{3}$, or $_{2} \mathrm{Al}_{4} \mathrm{O}_{9}$ phases, which indicate a cubic garnet crystal structure with lattice parameter of $1.2008 \mathrm{~nm}$. The excitation and emission spectra of nano-structured $\mathrm{Y}_{3} \mathrm{Al}_{5} \mathrm{O}_{12}: \mathrm{Ce}^{3+}$ phosphor using a xenon lamp as an excitation source are displayed in Fig. 2b. In previous work, the electronic transition of $\mathrm{Ce}^{3+}$ ion constitutes $4 \mathrm{f}^{1}$ in the ground state and $4 \mathrm{f}^{\circ} 5 \mathrm{~d}^{1}$ in the excited state ${ }^{23}$. The ground state is split into a doublet of two excitation bands at 338 and $450 \mathrm{~nm}$, which was attributed to electronic transition from ${ }^{2} \mathrm{~F}_{5 / 2}$ to the split excited $5 \mathrm{~d}$ states band in the ground state of the $\mathrm{Ce}^{3+}$ ion ${ }^{24}$. The ground state is split into a doublet of ${ }^{2} \mathrm{~F}_{7 / 2}$ and ${ }^{2} \mathrm{~F}_{5 / 2}$ because of spin-orbit interactions and the excited state is also split from the crystal field, which is affected by the surrounding ligand ions ${ }^{25}$. $\mathrm{Ce}^{3+}$ emission involves parity- and spin-allowed $5 \mathrm{~d} \rightarrow 4 \mathrm{f}$ electronic transition and consists of a yellow emitting primary band at $537 \mathrm{~nm}$ as well as a shoulder on the longer wavelength side, which is ascribed to electronic transition from $5 \mathrm{~d} \rightarrow{ }^{2} \mathrm{~F}_{5 / 2}$ and from $5 \mathrm{~d} \rightarrow{ }^{2} \mathrm{~F}_{7 / 2}$ Ce ions, respectively ${ }^{26}$. Also, in comparison with bulk $\mathrm{Y}_{3} \mathrm{Al}_{5} \mathrm{O}_{12}: \mathrm{Ce}^{3+}$ phosphor, the emission wavelength of the nano-structured $\mathrm{Y}_{3} \mathrm{Al}_{5} \mathrm{O}_{12}: \mathrm{Ce}^{3+}$ phosphor is shifted to the blue region. This phenomenon is explained as a crystal field strength around $\mathrm{Ce}^{3+}$ ion was somewhat reduced ${ }^{27}$. The luminescence in a nano-structured $\mathrm{Y}_{3} \mathrm{Al}_{5} \mathrm{O}_{12}: \mathrm{Ce}^{3+}$ phosphor is due to the transition between the energy levels of $\mathrm{Ce}^{3+}$ atoms as the luminescent center. After the sintering process, the surface of $\mathrm{Y}_{3} \mathrm{Al}_{5} \mathrm{O}_{12}: \mathrm{Ce}^{3+} \mathrm{CPP}(1.5 \mathrm{~mm} \mathrm{X} 1.5 \mathrm{~mm})$ was uniformly mirror-polished with a thickness of $100 \mu \mathrm{m}$ to convert the highly bright white colour via electroluminescence (EL) spectra as shown in Fig. 2c. Also, the real image of $\mathrm{Y}_{3} \mathrm{Al}_{5} \mathrm{O}_{12}: \mathrm{Ce}^{3+} \mathrm{CPP}$ under blue laser pointer $(1 \mathrm{~W})$ is indicated in the inset in Fig. 2c. The surface imgae of $\mathrm{Y}_{3} \mathrm{Al}_{5} \mathrm{O}_{12}: \mathrm{Ce}^{3+} \mathrm{CPP}$ is shown in Fig. 2d. EDX composition analyses revealed the presence of oxygen $(\mathrm{O})$, yttrium $(\mathrm{Y})$, and aluminum $(\mathrm{Al})$ elements in Fig. 2e. This result is supported by XRD analysis.

The final goal of this study is to use $\mathrm{Y}_{3} \mathrm{Al}_{5} \mathrm{O}_{12}: \mathrm{Ce}^{3+} \mathrm{CPP}$ in $445 \mathrm{~nm}$ emitting blue LDs for white light generation in automotive lighting. To achieve this goal, it is essential to analyze the luminous properties including the luminous emittance, luminous flux, conversion efficiency, emission spectra, CRI, and CCT of the prepared samples under blue laser excitation at $445 \mathrm{~nm}$. Figure 3a presents the luminous emittance of the white LD package under blue laser excitation at $445 \mathrm{~nm}$. With increasing blue incident power, the luminous emittance of $\mathrm{Y}_{3} \mathrm{Al}_{5} \mathrm{O}_{12}: \mathrm{Ce}^{3+} \mathrm{CPP}$ 

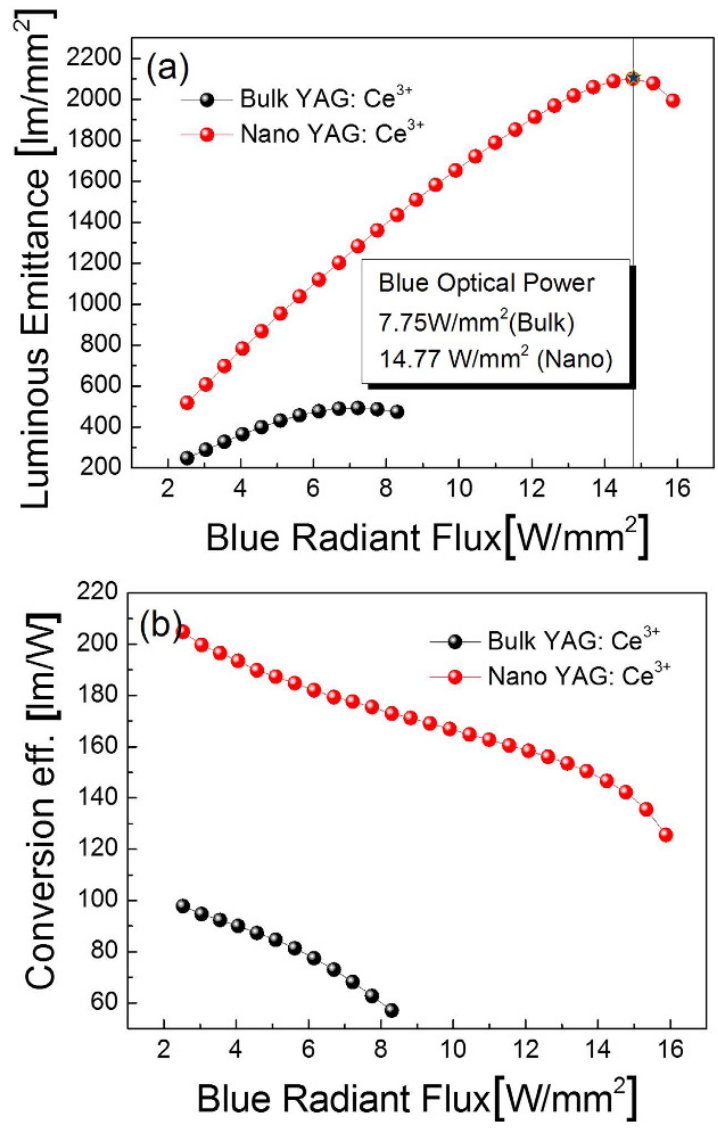

Figure 3. Luminous properties of $\mathrm{Y}_{3} \mathrm{Al}_{5} \mathrm{O}_{12}: \mathrm{Ce}^{3+}$ ceramic phosphor plate under a blue laser diode at $445 \mathrm{~nm}$. (a) emittance properties (b) conversion efficiency, repectively. a.u., arbitrary unit.

\begin{tabular}{|l|c|c|c|c|c|c|}
\hline \multirow{2}{*}{ Type } & \multirow{2}{*}{} & & \multicolumn{2}{|c|}{$\begin{array}{c}\text { Chromaticity } \\
\text { coordinate }\end{array}$} & \\
\cline { 5 - 6 } & \multirow{2}{*}{ CCT } & $\mathbf{R a}$ & $\mathbf{x}$ & $\mathbf{y}$ & Current (mA) & $\mathbf{l m} / \mathbf{u m}$ \\
\hline Bulk YAG: $\mathrm{Ce}^{3+} \mathrm{CPP}$ & 9938 & 53.9 & 0.289 & 0.271 & $400 \mathrm{~mA}$ & 1.285 \\
\hline Nano-structure YAG: $\mathrm{Ce}^{3+} \mathrm{CPP}$ & 6052 & 54.2 & 0.321 & 0.332 & $400 \mathrm{~mA}$ & 2.691 \\
\hline
\end{tabular}

Table 1. Luminous characteristics of nano-structure based $\mathrm{Y}_{3} \mathrm{Al}_{5} \mathrm{O}_{12}: \mathrm{Ce}^{3+}$ ceramic phosphor plate compared with bulk $\mathrm{Y}_{3} \mathrm{Al}_{5} \mathrm{O}_{12}: \mathrm{Ce}^{3+}$ one. *The rated current of the $445 \mathrm{~nm}$ blue laser diode. Thickness of each phosphor plate: $100 \mathrm{um}$.

is linearly increased. This is attributed to the increased number of electrons pumped up to the excited state of $\mathrm{Ce}^{3+}$ ions as a function of the increased blue incident power. The maximum luminous emittance value for $\mathrm{Y}_{3} \mathrm{Al}_{5} \mathrm{O}_{12}: \mathrm{Ce}^{3+} \mathrm{CPP}$ is using the nano-structure $\mathrm{Y}_{3} \mathrm{Al}_{5} \mathrm{O}_{12}: \mathrm{Ce}^{3+}$ phosphor obtained at a blue radiant flux density of $14.77 \mathrm{~W} / \mathrm{mm}^{2}$. This means that the $\mathrm{Y}_{3} \mathrm{Al}_{5} \mathrm{O}_{12}: \mathrm{Ce}^{3+}$ ceramic phosphor plate can be applied as a yellow emitting converter in LD applications. However, luminous saturation comes about at high blue radiant flux density due to the thermal quenching effect, which implies that the luminance of the $\mathrm{Y}_{3} \mathrm{Al}_{5} \mathrm{O}_{12}: \mathrm{Ce}^{3+} \mathrm{CPP}$ cannot be improved further.

Figure $3 \mathrm{~b}$ depicts the conversion efficiency of $\mathrm{Y}_{3} \mathrm{Al}_{5} \mathrm{O}_{12}: \mathrm{Ce}^{3+} \mathrm{CPP}$ with increasing blue incident power. When the incident power increases, the conversion efficiency decreases gradually. Both the luminous flux and conversion efficiency of $\mathrm{Y}_{3} \mathrm{Al}_{5} \mathrm{O}_{12}: \mathrm{Ce}^{3+} \mathrm{CPP}$ using the nano-structure $\mathrm{Y}_{3} \mathrm{Al}_{5} \mathrm{O}_{12}: \mathrm{Ce}^{3+}$ phosphor indicates better luminous properties than those of bulk $\mathrm{Y}_{3} \mathrm{Al}_{5} \mathrm{O}_{12}: \mathrm{Ce}^{3+}$ phosphor. This is ascribed to the effect of temperature during the fabrication of ceramic phosphor plates. Because the sintering process for ceramic phosphor plates is relatively culminated, the packing density of CPP using nano-structure $\mathrm{Y}_{3} \mathrm{Al}_{5} \mathrm{O}_{12}: \mathrm{Ce}^{3+}$ phosphor results in more outstanding luminous properties than for bulk $\mathrm{Y}_{3} \mathrm{Al}_{5} \mathrm{O}_{12}: \mathrm{Ce}^{3+}$ in Table 1. In nano-structure $\mathrm{Y}_{3} \mathrm{Al}_{5} \mathrm{O}_{12}: \mathrm{Ce}^{3+}$ phosphors, the micro structures of the ceramic phosphor plate are more perfectly formed than bulk $\mathrm{Y}_{3} \mathrm{Al}_{5} \mathrm{O}_{12}: \mathrm{Ce}^{3+}$. The densification and grain growth also gradually improved because of higher purity nano precursors, homogeneity, low degree of agglomeration, good crystallinity and low temperature sintering. These results shows that CPP using the nano-structure $\mathrm{Y}_{3} \mathrm{Al}_{5} \mathrm{O}_{12}: \mathrm{Ce}^{3+}$ phosphors have a finer and more uniform microstructure, as shown in Supplementary Information Fig. S1. 

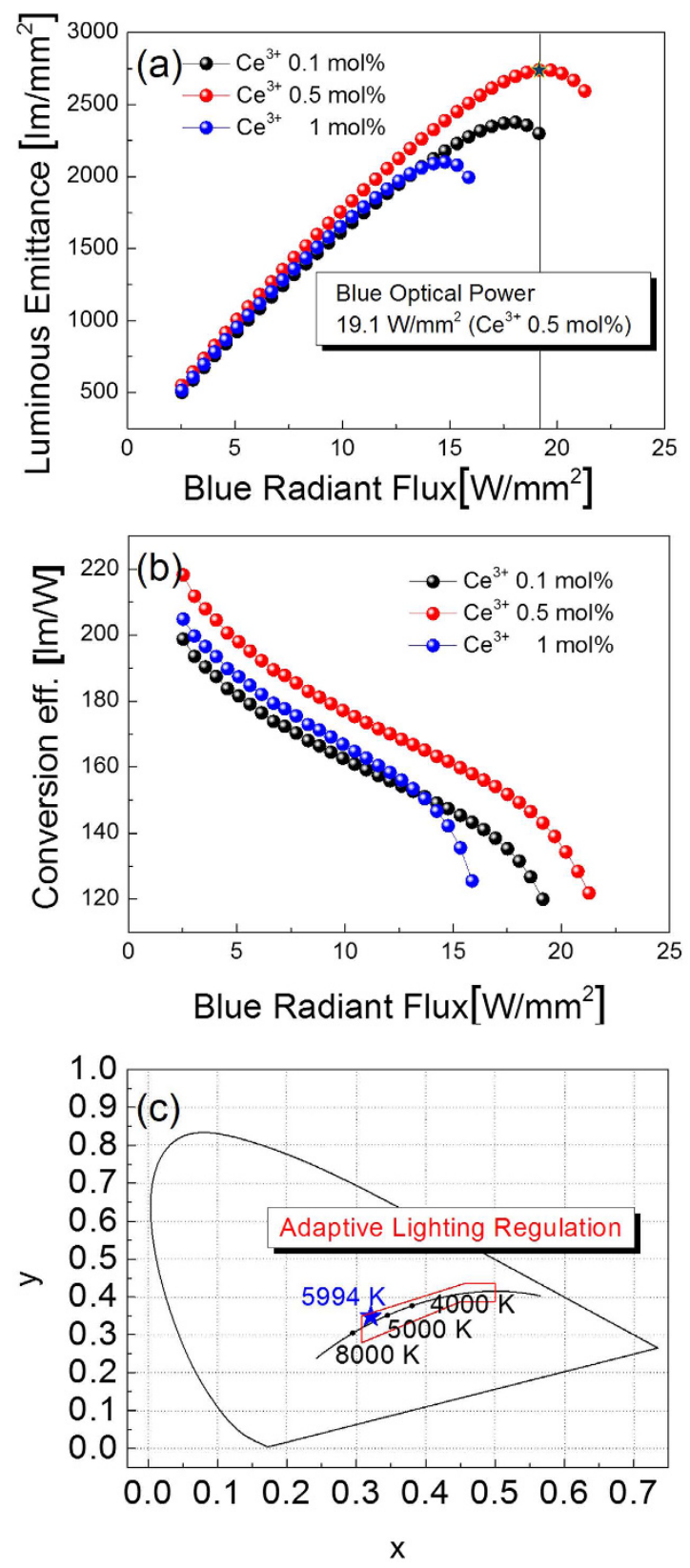

Figure 4. Luminous properties of $\mathrm{Y}_{3} \mathrm{Al}_{5} \mathrm{O}_{12}: \mathrm{Ce}^{3+}$ ceramic phosphor plate with increasing the $\mathrm{Ce}^{3+}$ ion concentration under a blue laser diode at $445 \mathrm{~nm}$. (a) emittance properties (b) conversion efficiency, repectively. a.u., arbitrary unit (c) CIE colour coordinates.

Figure 4a compares the changes in luminous emittance as a function of $\mathrm{Ce}^{3+}$ concentration under a blue laser diode at $445 \mathrm{~nm}$. Luminous emittance increased with increasing amounts of $\mathrm{Ce}^{3+}$, up to about $0.5 \mathrm{~mol} \%$, and the highest intensity was observed for CPP with $0.5 \mathrm{~mol} \% \mathrm{Ce}^{3+}$ ions. The value of illuminance is $2733 \mathrm{~lm} / \mathrm{mm}^{2}$. On the other hand, the illuminance value was degraded by $1 \mathrm{~mol} \% \mathrm{Ce}^{3+}$ ions. This means that the luminous emittance decreases with increasing blue incident power at $14.2 \mathrm{~W} / \mathrm{mm}^{2}$. The Supplementary Information in Fig. S2 suggests that $\mathrm{Y}_{3} \mathrm{Al}_{5} \mathrm{O}_{12}: \mathrm{Ce}^{3+}$ can be applied as white conversion materials with high blue incident power density. As demonstrated in Fig. $4 \mathrm{~b}$, the white conversion efficiency of $\mathrm{Y}_{3} \mathrm{Al}_{5} \mathrm{O}_{12}: \mathrm{Ce}^{3+} \mathrm{CPP}$ is improved with increasing blue incident power. When the blue incident power is $19.1 \mathrm{~W} / \mathrm{mm}^{2}$, the conversion efficiency decreases abruptly from $218 \mathrm{~lm} / \mathrm{W}$ to $120 \mathrm{~lm} / \mathrm{W}$ due to thermal quenching. Figure $4 \mathrm{c}$ presents the CIE colour coordinates. The calculated CCT value of the nano-structured $\mathrm{Y}_{3} \mathrm{Al}_{5} \mathrm{O}_{12}$ : $\mathrm{Ce}^{3+} \mathrm{CPP}$ with $0.5 \mathrm{~mol} \% \mathrm{Ce}^{3+}$ ions was $5994 \mathrm{~K}$. This is attributed to the daylight $(5500-6000 \mathrm{~K})$ for adaptive lighting regulation.

We believe that CPP using the nano-structure $\mathrm{Y}_{3} \mathrm{Al}_{5} \mathrm{O}_{12}: \mathrm{Ce}^{3+}$ will act as a candidate for the automotive lightings. 


\section{Conclusion}

In summary, we fabricated $\mathrm{Y}_{3} \mathrm{Al}_{5} \mathrm{O}_{12}: \mathrm{Ce}^{3+} \mathrm{CPP}$ using nano-structured phosphor under high-power blue radiant flux for white generation in automotive lighting. The synthesis technique, crystal structure, and luminous characteristics are investigated. Nano-structure based $\mathrm{Y}_{3} \mathrm{Al}_{5} \mathrm{O}_{12}: \mathrm{Ce}^{3+} \mathrm{CPP}$ exhibited an increase in luminous emittance, luminous flux and conversion efficiency compared to $\mathrm{Y}_{3} \mathrm{Al}_{5} \mathrm{O}_{12}: \mathrm{Ce}^{3+} \mathrm{CPP}$ with bulk phosphor. By applying the $\mathrm{Y}_{3} \mathrm{Al}_{5} \mathrm{O}_{12}: \mathrm{Ce}^{3+} \mathrm{CPP}$ to blue LD chips, we obtained suitable white light with $2733 \mathrm{~lm} / \mathrm{mm}^{2}, 1424.6 \mathrm{~lm}, 218 \mathrm{~lm} / \mathrm{W}$, CRI value of 54.2 and CCT value of $5994 \mathrm{~K}$. We believe that $\mathrm{Y}_{3} \mathrm{Al}_{5} \mathrm{O}_{12}: \mathrm{Ce}^{3+} \mathrm{CPP}$ using nano phosphor is one of the simplest ways to obtain high luminous properties. Thus, our results suggest that this material can potentially serve as remote phosphors in phosphor converted LDs for white light generation.

\section{References}

1. Shuji, N., Masayuki, S., Naruhito, I. \& Shin-ichi, N. High-Brightness InGaN Blue, Gree and Yellow Light-Emitting Diodes with Quantum Well Structure. Jpn. J. Appl. Phy. 23, L797-L799 (1995).

2. Pimputkar, S., Speck, J. S., DenBaars, S. P. \& Shuji, N. Prospects for LED lighting. Nat. Photonics. 3, 180-182 (2009).

3. Steigerwald, D. A. et al. Illumination With Solid State Lighting Technology. IEEE J. Sel. Top. Quantum Electron. 8, 310-320 (2002).

4. Humphreys, C. J. Solie-State Lighting. MRS BULL. 33, 459-470 (2008).

5. Toshihiko, K. \& Masao, N. Fundamental Analysis for Visible-Light Communications System using LED Lights. IEEE Trans. Consum. Electron. 50, 100-107 (2004).

6. Hisayoshi, D. et al. A novel phosphor for glareless white light-emitting diodes. Nat. Commun. 3, 1-8 (2012).

7. Schlotter, P. et al. Fabrication and characterization of GaN/InGaN/AlGaN double heterostructure LEDs and their application in luminescence conversion LEDs. Mater. Sci. Eng. B. 59, 390-394 (1999).

8. Basu, C., Meinbardt-Wollweber, M. \& Bernhard R. Lighting with laser diodes. Adv. Opt. Techn. 2, 313-321 (2013).

9. Chi, Y. C. et al. Phosphorus Diffuser Diverged Blue Laser Diode for Indoor Lighting and Communication. Sci. Rep. 5, 18690 (2015).

10. Schnitzer, I., Yablonovitch, E., Caneau, C., Gmitter, T. J. \& Scherer, A. 30\% external quantum efficiency from surface textured, thin-film light-emitting diodes. Appl. Phys. Lett. 63, 2174-2176 (1993).

11. Raukas, M. et al. Ceramic Phosphors for Light Conversion in LEDs. ECS J. Solid State Sci. Technol. 2, R3168-R3176 (2013).

12. Tsai, C. C. et al. Ultra-High Thermal-Stable Glass Phosphor Layer for Phosphor-Converted White Light-Emitting Diodes. J. Display Technol. 9, 427-432 (2013).

13. Ikesue, A., Furusato, I. \& Kamato, K. Fabrication of Polycrytalline, Transparent YAG Ceramics by a Solid-State Reaction Method. J. Am. Ceram. Soc. 78, 225-228 (1995).

14. Xu, X. et al. Synthesis of Monodispersed Spherical Yttrium Aluminum Garnet (YAG) Powders by a Homogeneous Precipitation Method. J. Am. Ceram. Soc. 95, 3821-3826 (2012).

15. Veith, M. et al. Low temperature synthesis of nanocrystalline Y3Al5O12 (YAG) and Ce-doped Y3Al5O12 via different sol-gel methods. J. Mater. Chem. 9, 3069-3079 (1999).

16. Yang, Z., Li, X., Yang, Y. \& Li, X. The influence of different conditions on the luminescent properties of YAG:Ce phosphor formed by combustion. J. Lumin. 122-123, 707-709 (2007).

17. Kang, Y. C., Lenggoro, I. W., Park, S. B. \& Okuyama, K. YAG:Ce phosphor particles prepared by ultrasonic spray pyrolysis. Mater. Res. Bull. 35, 789-798 (2000).

18. Nishiura, S., Tanabe, S., Fujioka, K. \& Fujimoto, Y. Properties of transparent Ce:YAG ceramic phosphors for white LED. Opt. Mater. 33, 688-691 (2011).

19. Zhu, Y. Narendran, N. \& Gu, Y. Investigation of the Optical Properties of YAG:Ce phosphor. Proc. of SPIE. 6337, 63370S-1-63370S-8 (2006).

20. Fujita, S., Yoshihara, S., Sakamoto, A., Yamamoto, S. \& Tanabe, S. YAG glass-ceramic phosphor for white LED (I): background and development. Proc. of SPIE. 5941, 594111-1-594111-7 (2005).

21. Chi, Y. C. et al. 450-nm GaN laser diode enables high-speed visible light communication with 9-Gbps QAM-OFDM. Opt. Express. 23, 13051-13059 (2015).

22. Retamal, J. R. et al. B.S. 4-Gbit/s visible light communication link based on 16-QAM OFDM transmission over remote phosphorfilm converted white light by using blue laser diode. Opt. Express. 23(26), 33656-33666 (2015).

23. Paulose, P. I., Jose, G., Thomas, V., Unnikrishnan, N. V. \& Warrier, M. K. R. Sensitized fluorescence of Ce3p/Mn2p system in phosphate glass. J. Phys. Chem. Solids. 64, 841-846 (2003).

24. Jacobs, R. R., Krupke, W. F. \& Weber, M. J. Measurement of excited-state-absoprtion loss for $\mathrm{Ce}^{3+}$ in $\mathrm{Y}_{3} \mathrm{Al}_{5} \mathrm{O}_{12}$ and implications for tunable $5 \mathrm{~d} \rightarrow 4 \mathrm{f}$ rare-earth lasers. Appl. Phys. Lett. 33, 410-412 (1978).

25. Pan, Y., Wu, M. \& Su, Q. Tailored photoluminescence of YAG:Ce phosphor through various methods. J. Phys. Chem. Solids. 65, $845-850$ (2004).

26. Kasuya, R., Kawano. A \& Isobe, T. Characteristic optical properties of transparent color conversion film prepared from YAG:Ce ${ }^{3+}$ nanoparticles. Appl. Phys. Lett. 91, 111916-1-111916-3 (2007).

27. Byun, H. J., Song, W. S., Kim, Y. S. \& Yang, H. S. Solvothermally grown $\mathrm{Ce}^{3+}$-doped $\mathrm{Y}_{3} \mathrm{Al}_{5} \mathrm{O}_{12}$ colloidal nanocrystals: spectral variations and white LED characteristics. J. Phys. D: Appl. Phys. 43, 195401-195406 (2010).

\section{Acknowledgements}

This research was supported by the Basic Science Research Program through the National Research Foundation of Korea (NRF), funded by the Ministry of Education (NRF-2013R1A1A2059280). This work was supported by the Korea Institute of Energy Technology Evaluation and Planning(KETEP) and the Ministry of Trade, Industry \& Energy(MOTIE) of the Republic of Korea (No. 20153030012560).

\section{Author Contributions}

Y.H.S. and E.K.J. prepared the samples and performed the characterization for most of the analyzed samples and written the manuscript. E.Y.K. and B.W.J. carry out analyzed data, designed the experiments. M.K.J. carried out part of device fabrication. D.H.Y. contributed the conception in this paper and analysis of the data.

\section{Additional Information}

Supplementary information accompanies this paper at http://www.nature.com/srep

Competing financial interests: The authors declare no competing financial interests. 
How to cite this article: Song, Y. H. et al. High power laser-driven ceramic phosphor plate for outstanding efficient white light conversion in application of automotive lighting. Sci. Rep. 6, 31206; doi: 10.1038/srep31206 (2016).

(c) (i) This work is licensed under a Creative Commons Attribution 4.0 International License. The images or other third party material in this article are included in the article's Creative Commons license, unless indicated otherwise in the credit line; if the material is not included under the Creative Commons license, users will need to obtain permission from the license holder to reproduce the material. To view a copy of this license, visit http://creativecommons.org/licenses/by/4.0/

(C) The Author(s) 2016 